\title{
Correction: Smartphone Cognitive Behavioral Therapy as an Adjunct to Pharmacotherapy for Refractory Depression: Randomized Controlled Trial
}

Akio Mantani ${ }^{1}$, MD, PhD; Tadashi Kato ${ }^{2}$, MD; Toshi A Furukawa ${ }^{3}, \mathrm{MD}, \mathrm{PhD}^{\ddagger}$; Masaru Horikoshi ${ }^{4}, \mathrm{PhD}$; Hissei Imai $^{3}, \mathrm{MD}, \mathrm{PhD}$; Takahiro Hiroe ${ }^{5}, \mathrm{MD}, \mathrm{PhD}$; Bun $\mathrm{Chino}^{6}, \mathrm{MD}, \mathrm{PhD}$; Tadashi Funayama ${ }^{7}, \mathrm{MD}, \mathrm{PhD}$; Naohiro Yonemoto $^{8}$, MPH; Qi Zhou ${ }^{9}, \mathrm{PhD} ; \mathrm{Nao}$ Kawanishi $^{10}, \mathrm{PhD}$

${ }^{1}$ Mantani Mental Clinic, Hiroshima, Japan

${ }^{2}$ Aratama Kokorono Clinic, Nagoya, Japan

${ }^{3}$ Department of Health Promotion and Human Behavior, School of Public Health, Graduate School of Medicine, Kyoto University, Kyoto, Japan

${ }^{4}$ National Center of Neurology and Psychiatry, Kodaira, Japan

${ }^{5}$ Waseda Clinic, Kani, Japan

${ }^{6}$ Ginza Taimei Clinic, Tokyo, Japan

${ }^{7}$ Funayama Mental Clinic, Nagoya, Japan

${ }^{8}$ Department of Biostatistics, School of Public Health, Graduate School of Medicine, Kyoto University, Kyoto, Japan

${ }^{9}$ Department of Health Research Methods, Evidence, and Impact, McMaster University, Hamilton, ON, Canada

${ }^{10}$ Advanced Telecommunications Research Institute International, Kyoto, Japan

"the FLATT Investigators

\section{Corresponding Author:}

Toshi A Furukawa, MD, PhD

Department of Health Promotion and Human Behavior, School of Public Health, Graduate School of Medicine, Kyoto University Yoshida Konoe-cho,

Sakyo-ku,

Kyoto, 606-8501

Japan

Phone: 81757539491

Email: furukawa@kuhp.kyoto-u.ac.jp

\section{Related Article:}

Correction of: http://www.jmir.org/2017/11/e373/

(J Med Internet Res 2018;20(8):e11702) doi: 10.2196/11702

The authors of "Smartphone Cognitive Behavioral Therapy as an Adjunct to Pharmacotherapy for Refractory Depression: Randomized Controlled Trial" (J Med Internet Res 2017;19(11):e373) incorrectly listed "September 2, 2015" as the starting date of patient eligibility assessment. However, "September 2, 2014" is the correct date.
The correction will appear in the online version of the paper on the JMIR website on August 31, 2018, together with the publication of this correction notice. Because this was made after submission to PubMed, Pubmed Central, and other full-text repositories, the corrected article also has been re-submitted to those repositories.

Edited by G Eysenbach; this is a non-peer-reviewed article. Submitted 25.07.18; accepted 17.08.18; published 31.08.18.

Please cite as:

Mantani A, Kato T, Furukawa TA, Horikoshi M, Imai H, Hiroe T, Chino B, Funayama T, Yonemoto N, Zhou Q, Kawanishi N

Correction: Smartphone Cognitive Behavioral Therapy as an Adjunct to Pharmacotherapy for Refractory Depression: Randomized Controlled Trial

J Med Internet Res 2018;20(8):e11702

URL: http://www.jmir.org/2018/8/e11702/

doi: $\underline{10.2196 / 11702}$

PMID: 30168797 
(C)Akio Mantani, Tadashi Kato, Toshi A Furukawa, Masaru Horikoshi, Hissei Imai, Takahiro Hiroe, Bun Chino, Tadashi Funayama, Naohiro Yonemoto, Qi Zhou, Nao Kawanishi. Originally published in the Journal of Medical Internet Research (http://www.jmir.org), 31.08.2018. This is an open-access article distributed under the terms of the Creative Commons Attribution License (https://creativecommons.org/licenses/by/4.0/), which permits unrestricted use, distribution, and reproduction in any medium, provided the original work, first published in the Journal of Medical Internet Research, is properly cited. The complete bibliographic information, a link to the original publication on http://www.jmir.org/, as well as this copyright and license information must be included. 